\title{
An Empirical Research on Chinese Teachers Transition to US Schools: Pedagogical Implications and Teacher Training Program*
}

\begin{abstract}
LIU Xue-mei
Binzhou University, Binzhou, China

With the further promotion and popularization of teaching Chinese in America, more and more Chinese teachers are needed in the US schools to teach the Chinese language. The US education system needs them to transit their traditional teaching pedagogy to adapt the new environment. In order to help Chinese teachers set up appropriate strategies in Chinese teaching in America, the author chooses 29 participants from the teacher training summer program at George Mason University and has done an empirical research. Through questionnaire, this paper analyzes the data collected from the teacher training summer program and puts forward the following strategies of the Chinese teachers' transition: the changing of teaching strategies, the quality improvement of the Chinese curriculum, and the necessity of learning culture.
\end{abstract}

Keywords: Chinese teaching, teaching pedagogy, teaching system, teaching curriculum

\section{Introduction}

More and more Chinese teachers are needed in the US schools to teach the Chinese language. Most of these teachers are native speakers. They either came to the US recently or they received their high school and/or college education outside of the US. Every one of these foreign teachers is or will be facing transitioning challenges in the US school systems. Their education backgrounds are very different from the US education system. They are not adequately prepared to face the multi-cultural and social-eco issues confronting many American school teachers. There was one example of a volunteer Chinese teacher who chose to return to China after experiencing the cultural shock in a Washington DC public school. Many other Chinese teachers are trying their best to fit into the American education system and to teach Chinese the best way they can. Teacher re-certification or some focused retraining in an accredited American institution becomes a pre-requisite for these foreign teachers to smoothly transition into our public schools.

We held two teacher training summer programs at George Mason University during the past two years. More than 40 in-service and pre-service Chinese teachers participated in the training. We believe we received some quality feedback from these two summer programs which we would like to share in the hopes of stimulating

\footnotetext{
${ }^{*}$ This paper is the 12th Five-year Plan Subject’s initial achievements for Shandong Provincial Educational Science: A Case Study of Binzhou University on Optimizating English Education Major’s Practical Personnel Cultivating Pattern for Local Universities. LIU Xue-mei, associate professor, master, Foreign Languages Department, Binzhou University.
} 
some dialogue and further research. Hopefully, any future teacher training program can be better targeted and enhanced to more efficiently train these teachers in the transitioning process.

\section{Literature Review}

As the population of the US becomes more diverse (Banks, 2006; Irvine, 2003), both challenges and opportunities are created for our education systems. Education scholars have called for changes in teacher education programs to prepare for the increasingly diverse student population in America's schools (Banks, 2006; Ladson-Billings, 2000; Villegas \& Lucas, 2002). According to Gay and Howard (2000), regarding the situation of current education in FL (foreign language) teaching in US schools - never before have public school teachers in the US been faced with the challenge for meeting the needs of so many diverse learners. The teaching force in the US is decreasing while the student population is increasingly diverse. Therefore, it is important to help prospective teachers develop the competencies necessary to meet the needs of these learners. It is indeed a difficult and complete task for teachers and educators. In addition, we need to review the limited literature that addresses the role of teacher educators in preparing pre-service teachers to work with diverse students.

According to Milner and Smithey's (2003) theory, for pre-service teachers-those individuals who are teacher candidates in teacher education programs—often enter classrooms culturally, racially, and ethnically incompetent. In other words, these teachers have not developed the skills necessary to be sensitive to cultural differences. Moreover, many pre-service teachers have never had significant interactions with students from diverse backgrounds and, as a result, their knowledge and understanding where diversity issues are concerned are imprecise and often result in cultural and racial mismatches. In short, many pre-service teachers have never attended schools themselves with individuals from diverse backgrounds, or lived in racially diverse neighborhoods. In light of this lack of exposure to diverse populations and in the absence of intense study and reflection, pre-service teachers may rely on stereotypical conceptions of diverse students to inform their future work as teachers.

As pre-service teachers, they need to know a range of information-from how best to organize their activities when they present themselves in the classroom to how to communicate with parents. In addition, teachers need to know their subject matter, and they need to understand the contextual idiosyncrasies as they work to teach that content. How best to help teachers develop these multiple layers of knowledge has long been a struggle for teacher education programs. Perhaps the struggles that teacher education programs are facing stem from the peculiar, multifaceted nature of teaching and learning to teach. Essentially, the skill of linking theory to practice, connecting practice to theory, and the conceptual change that is necessary for teachers to move from novice to expert in an era of reform are complicated issues that require some serious rethinking and re-conceptualization. Thus, teacher education programs are working hard to meet the "knowledge and conceptual development" needs of teachers to inform their practice, as has been the case for several decades (Milner \& Smithey, 2003). So, an important goal of teacher education programs should be to identify pre-service teachers who are able to acquire the knowledge, skills, and perspectives needed to become insiders within the communities in which they teach. Teacher education programs, in collaboration with school system educators, should address the career needs of teachers as they face the joys and challenges of diverse classrooms, helping teachers to understand and change their practices around diversity (Causey, Thomas, \& Armento, 2000). 
It is clear that the knowledge prospective teachers acquire in teacher education programs provides a framework and foundation for how these teachers teach (Easter, Shultz, Neyhart, \& Reck, 1999). In the research, the researchers pay much attention to apply methods that help teachers change their beliefs and attitudes about culturally diverse students. Johnson (1996) recognized a need for language teacher education programs to be able to provide a more realistic view of classroom life so that the experience of becoming a language teacher would be “less like 'hazing' and more like professional development” (pp. 30-49).

Yet, teacher education programs have not had a successful history of adequately preparing beginning teachers for this transition to the real world of the school mainly because of a perception that each first year teaching experience is so unique that generalizations may be difficult to derive from these specific experiences (Northfield \& Gunstone, 1997). Under such circumstance, we need to provide appropriate training to improve their teaching skills and guide them to adapt to the US environment. Biggs, Kember, and Leung (2001) suggested that there were interactions between the students' perceptions and the contextual factors. A good learning environment is one that can help promote deep learning; and a poor learning environment, on the other hand, is conducive to the rote learning strategy. As we know, learning approaches are not innate, fixed individual traits; rather, they are profoundly affected by the learning environment such as teaching methods, workloads, classroom climate, assessment demands, and institution requirements. In other words, an individual student's learning approach may adjust to the specific learning environments (Kember \& Gow, 1994).

From the above analysis, we see that it is important for pre-service teachers and in-service teachers to take some additional training. This would be especially true for the teachers from other countries who want to teach in US schools. With different cultures, customs, and diverse students, it is a big challenge for pre-service teachers to face and have to overcome. Biggs (1996) put forward some suggestions to help teachers to organize classroom activities. He suggested that a deep learning environment usually possess the following characteristics: such as smaller class size, student-centeredness, group work, interactions, problem solving, knowledge exploration, and qualitative and classroom-based assessment methods. On the other hand, the typical surface-learning setting is featured by teacher-dominated big class, passive learning, emphasis on drills and repetition, as well as highly stressful memorization-based assessments. In addition, multicultural teacher education literature advocates that pre-service teachers engage in a process that deconstructs the hidden structures of social reproduction that occur both inside and outside of the education system (Ladson-Billings, 2000; Villegas \& Lucas, 2002). More specifically, as Villegas and Lucas (2002) once mentioned that pre-service teachers should understand that social inequalities are produced and perpetuated through systematic discrimination and justified through a societal ideology of merit, social mobility, and individual responsibility.

\section{Purpose of the Study}

As evidenced in the literature review, prior research sheds some light on the understanding of the strategies which Chinese teachers usually choose in their classroom. This study seeks to validate and extend how to help Chinese teachers who plan to teach Chinese in US schools to transit their teaching ideas and methodologies through actually teaching pedagogy training and teaching practice in workshop.

This investigation set out to address the following research questions: (1) What are the expectations that Chinese teachers have for their teaching and their students as they enter US school?; and (2) What are the effects 
of the workshop on the teaching practices of Chinese teachers?

\section{Research Methodology}

\section{Participants}

All participants in this research consist of pre-service teachers and in-service teachers (altogether there were 29 participants: 19 Chinese and 10 Arabic). For this specific research, we only use responses from the Chinese teachers. Among Chinese participants, $21 \%$ of them have received their teaching licenses in the US, and $58 \%$ of them have been employed as a language teacher. Among the pre-service teachers, all of them have finished their two-month internships in US primary and middle schools. So, they have some basic ideas of the difference between teaching in China and in the US.

\section{Research Process and Results}

This research analysis is based on the data collected from the Star Talk 2009 Summer Institute at George Mason University. The first step of the research is pre-survey data collection, which means we have designed the questionnaire for the participants to complete according to their prior knowledge and experiences. The purpose of this part of the data collection is to analyze the teacher's roles and teaching methodologies in a Chinese classroom. All participants attended a one week workshop to learn the current teaching theories for US schools; and then they were assigned a teaching task to practice their teaching approach with some US elementary school students. After two weeks training, we carried out the post-survey data collection to analyze what the teachers should do in the US schools, their roles, and the teaching methodologies they should apply. Our research results are derived from a comparison between the two surveys. They are listed as follows (see Tables 1-7):

Table 1

Think Back to Your Own Language Learning Experiences. What Was the Role of the Teacher?/What Expectations Did the Teachers Have for the Students?

\begin{tabular}{llll}
\hline No. & Comments & N & $(\%)$ \\
\hline 1 & Student-oriented teaching method & 8 & 42 \\
2 & Traditional teacher-centered classroom & 1 & 58 \\
\hline
\end{tabular}

Among 19 responses, 58\% of the participants have the same preconceived concept of the teacher's role as their own language teachers in China. Teacher is the center of the class and guides students to learn vocabulary and drills, especially asks them to recite and memorize the rules of grammar so as to do some grammar exercises.

Table 2

What Are Some of the Differences Between Language Classrooms in the US and Language Classrooms in Your Own Country?

\begin{tabular}{llll}
\hline No. & Comments & N & $(\%)$ \\
\hline 1 & Grammar driven approach & 6 & 33 \\
2 & Teacher-centered method & 4 & 22 \\
3 & Culture and language proficiency & 3 & 17 \\
4 & Teaching environment & 3 & 17 \\
5 & Purpose of language teaching & 2 & 11 \\
\hline
\end{tabular}


For this question, there are altogether 18 valid responses, one participant did not answer the question. In the responses, 33.3\% of participants mentioned the traditional teaching methodology used in China is grammar translation method which pays much attention to the skill of reading and writing. In China, language teachers are the center of the classroom. Language learning and teaching usually follow the drills, translation work, and rote memorization of vocabulary and phrases. The grammar driven approach to teach language is the mainstream. Language learning mainly focuses on reading and writing. In the US schools, language learning focuses on listening and speaking, students are more involved in the learning process and there are more hands-on activities. It is no surprise that $22 \%$ of the participants mentioned that teacher is the center of the class. The teacher usually controls the class according to the teaching plan. In such an environment, the purpose of teaching is to finish specific teaching task(s) based on the curriculum instead of the real needs of students.

Table 3

What Do You Believe Are the Biggest Challenges Teaching the Students in US Schools?

\begin{tabular}{llll}
\hline No. & Comments & $\mathrm{N}$ & $(\%)$ \\
\hline 1 & Purpose of teaching language & 7 & 37 \\
2 & Culture differences & 6 & 31.4 \\
3 & Teaching skills & 3 & 15.8 \\
4 & Classroom management & 3 & 15.8 \\
\hline
\end{tabular}

Among the 19 responses, 37\% of participants indicated the purpose of teaching language is the major challenge for Chinese teachers in the US schools. Different teaching pedagogy affects the methods of classroom management. Another $31.4 \%$ of participants indicated that the biggest challenge is the cultural differences. For this group of participants, the need to adapt to the different cultural backgrounds of their students is greatest. How to cope with the different learning levels of the students within the classroom. These teachers need to be more aware and learn to use appropriate language and signals in order to avoid misinterpretation. The discussions during the training also provided us with some useful information related to this question. The purpose of teaching language in the US schools is to allow students to use the language to communicate. On the other hand, in China, language learning is naturally passive, and the purpose of learning is to gain knowledge for the exams they need to pass. Different purposes will definitely require different teaching approaches.

The culture differences also affect the classroom teaching approaches. It is very normal that teachers should be the center of the classroom teaching in China. Students usually listen to the teacher and do what teachers asked them to do. Everything that students need to know should be taught in the class. In China, for thousands of years the teacher has been held in high esteem. However, students in the US are not like that. They are more active in the class and would like to learn from different activities and have fun during their learning process. This is also a key issue in classroom management. Generally speaking, teachers were not challenged that much with classroom management issues in China. Students understand that they need to obey what the teacher asked them to do. The first thing a Chinese teacher in a US classroom will face is the classroom management issue, even though the number of the students in one class is less than what they have in a typical classroom in China. Efficient classroom rules, a student-centered teaching approach, and more meaningful classroom learning activities will motivate students to learn and will help with the classroom management. 
Table 4

What Concerns Do You Have Regarding Your Responsibilities as a Language Teacher in US School?

\begin{tabular}{llll}
\hline No. & Comments & $\mathrm{N}$ & $(\%)$ \\
\hline 1 & How to use language to communicate in real life & 6 & 33.3 \\
2 & Students' needs & 4 & 22.2 \\
3 & Culture differences & 3 & 16.7 \\
4 & Classroom management & 3 & 16.7 \\
5 & Modern technology & 2 & 11.1 \\
\hline
\end{tabular}

Among the 18 responses, one participant did not answer this question. Among participants, 33\% were concerned about how to use language to communicate in real life. The purpose of learning a FL is to communicate and obtain new information from others. As language teachers, we should know the importance of arousing students' interests in learning a FL and know how to integrate real life needs into the classroom environment. Another $22.2 \%$ of participants expressed the importance of a teacher's ability to assess the real needs of each student in the class. In addition, $11.1 \%$ participants mentioned that it was necessary for teachers to use modern technology in the classroom which could help them to design their teaching plan and create realistic exercises for students to practice.

Table 5

What Challenges Have You Faced in Implementing Collaborative, Learner-Centered Instruction and/or Assessment?

\begin{tabular}{llll}
\hline No. & Comments & $\mathrm{N}$ & $(\%)$ \\
\hline 1 & Classroom management & 9 & 47.3 \\
2 & Different levels of students & 3 & 15.8 \\
3 & Use target language to instruct & 3 & 15.8 \\
4 & Time management & 2 & 10.5 \\
5 & The real environment to implement & 1 & 5.3 \\
6 & Technology & 1 & 5.3 \\
\hline
\end{tabular}

To this question, $47.3 \%$ participants indicated that the biggest challenge they have faced is the classroom management. The teacher should adopt appropriate strategies to manage the classroom according to students' different levels, such as using technology to arouse students' interesting, design different levels’ of assessment based on differentiate needs. Another $15.8 \%$ of participants mentioned that it is hard for a teacher to use target language to guide students to carry on their assignment and activities. In addition, 10.5\% participants mentioned that it is difficult for new teachers to manage the teaching time appropriately.

Table 6

Were You Able to Overcome These Challenges, If So How?

\begin{tabular}{llrr}
\hline No. & Comments & $\mathrm{N}$ & $(\%)$ \\
\hline 1 & Yes (Different teaching strategies) & 12 & 63.2 \\
& Clear instructions & 4 & 21.2 \\
& On-going assessment & 3 & 15.8 \\
& Authentic materials & 3 & 15.8 \\
& Student center activities & 1 & 5.2 \\
& With the classroom teacher's help & 1 & 5.2 \\
\hline & Not yet & 7 & 36.8 \\
\hline
\end{tabular}


About $63.2 \%$ participants indicated that they can use different teaching strategies to overcome those challenges, such as giving clear instructions (21.2\%), having on-going assessments (15.8\%), using authentic materials (15.8\%), having more student-centered activities (5.2\%), and getting help from the classroom teachers (5.2\%). However, there are about 36.8\% who mentioned that they need help to overcome the challenges they face.

Table 7

What Other Kinds of Professional Development Do You Feel You Need to Transition to Us Teaching?

\begin{tabular}{llll}
\hline No. & Comments & $\mathrm{N}$ & $(\%)$ \\
\hline 1 & Learn more US culture & 5 & 26.3 \\
2 & Classroom management & 3 & 15.8 \\
3 & Differentiated instruction & 3 & 15.8 \\
4 & Training on technology & 3 & 15.8 \\
5 & US school system & 2 & 10.5 \\
6 & Child development & 2 & 10.5 \\
7 & More workshops & 1 & 5.3 \\
\hline
\end{tabular}

For this question, all participants expressed their needs in terms of future professional development. They would like to learn more about American culture (26.3\%), classroom management (15.8\%), differentiated instructions (15.8\%), modern technology (15.8\%), US school systems (10.5\%), child development (10.5\%), and workshops/training program (5.3\%).

\section{Analysis and Suggestions}

\section{The Changing Teaching Strategy}

From the above survey, we know that traditionally, about 58\% FL teachers used a grammar-based approach as the teaching method. However, in today's global and changing world, the traditional Chinese way of teaching second language or FL is no longer sufficient and appropriate. During the past two decades, the trend of teaching is shifting to more communicative and interactive approaches (Lee \& Vanpatten, 2003). According to Widdowson (1998), language instruction for communicative approaches must "come to terms with the learner's reality and somehow create contextual conditions that are appropriate to them and that will enable them to authenticate it as discourse on their own terms” (p. 712). Thus, it becomes a big challenge for second language teachers today to develop a wider array of competences (Velez-Rendon, 2002). Before making decisions regarding teaching methodology, teachers or school administrators have to ascertain their goals and the age of students. If the goal of teaching FL is proficiency, full-immersion education taught by teachers who are experts in the language is a strong method (Genesee, 1994). In addition, other effective ways for teaching a FL for older students include direct teaching, systematic practice, and ample chances for conversation (Resnick, 2006). No matter what kind of teaching method those teachers use, they have to find a balance between structure (e.g., knowledge of grammar and language structure) and meaning (e.g., student's motivation). A student's FL learning outcome is affected by age and type of exposure to the language. FL learning is not something that takes place immediately. It takes time and money as well as requires deliberate planning by the school administrator or policy maker. 


\section{Enhance the Quality of the Chinese Curriculum}

Usually, Chinese teachers have to teach different grades at one school. They design the curriculum and teaching materials for different student age groups. How to design curricula that are useful and interesting is very critical. A well designed curriculum arouses students' learning motivation and increases studying efficiency. Whether the curriculum fits in with the cognitive developmental state of a child's age is another significant concern. The early stages of establishing a Chinese Language Program afford American educators or policy makers the chance to control the quality of Chinese teachers and the curriculum.

In recent years, the federal government has come to understand many of the problems with teacher preparation programs and has repeatedly called for curriculum reform, innovation in program design, and greater emphasis on the practical component of pre-service education (Ministry of Education, 1999, 2001; State Council, 2001). Many teacher educators are also critically reviewing the existing programs, introducing international developments in teacher education, and suggesting directions in which the current curriculum can be reformed (K. K. HE, 2002; HUANG, 2002; LIU, 2002; L. SHI, 2002; Q. H. SHI, 2002). However, curricular reform is still at the stage of conceptual deliberation, and curriculums and programs that embody new ideas about initial teacher education have yet to appear. Furthermore, even if such curriculums and programs can be expected in the near future, it is still too early to predict significant improvements in the quality of teacher preparation, because many of the instructional practices common to teacher education programs also need to be critically examined and changed.

\section{The Necessity to Learn the Culture}

A typical assumption in second language education is to add on a cultural component to the basic four skills like icing on a cake. In contrast, Kramsch (1994) argued that cultural context should be the core of a second language curriculum. By this she meant that the cultural context of language ought to be made explicit through social interaction in the classroom, the use of stories, discourses, literary texts, and authentic texts. Without such a change in thinking, misunderstandings can easily arise because learners may acquire particular language forms without realizing their cultural significance. Vocabulary, for instance, may aid learners in understanding what is important to a culture, how native speakers classify experience, provide a record of cultural borrowings, and reveal attitudes to foreign words and ideas (Saville-Troike, 1996; Lakoff, 1987; Myers, 1997). Compound words, for example, may be a source for understanding Chinese beliefs and values. Teachers could organize these into meaningful groups in order to make different Chinese ways of thinking explicit. FL teachers with knowledge of their students' mother tongues could also use vocabulary as a means to compare and contrast cultural values.

Another area for language educators and researchers to explore in relation to culture and language is the discourse level. A recent study of Chinese American children in a Chinese heritage school in the US (A. HE, 1999) examined some ways that Chinese cultural values are revealed through the interactional and grammatical organization of teachers' directives. A. HE (1999, p. 16) claimed that the teacher draws upon the notion of filial gratitude to impress on students the importance of fulfilling parental expectations. This strategy is employed as a way to get inattentive students to pay attention. While A. HE's interpretation is open to debate, it remains true that Chinese cultural values can be evident at a discourse level. One specific technique to make this explicit for adult CFL (Chinese Foreign Language) learners, for example, would be to identify cross-cultural 
misunderstandings (LIAO, 1997) that arise in CFL classrooms, Chinese literature or Chinese movies. As teachers notice cross-cultural issues more frequently, they might be able to diagnose and predict areas of cultural conflict.

As we discussed before, the classroom management is one of the big challenges for most Chinese teachers. From our own teaching experiences we realize that having students involved in the teaching process would be a great way to get students motivated to learn, and it helps a lot with the classroom management. For example, asking Chinese level 3 students to lead the class for the vocabulary review. Each student was assigned one lesson. During class, two level 3 students will conduct the teaching of vocabulary, and during the next class period conduct the assessment for each of their lessons. What surprised us was that all level 3 students were very well prepared to teach their lessons and had different activities to help their teaching. Each student was looking forward to some teaching time and the whole class was very active and students enjoyed their learning by experiencing different teaching styles and practice activities. The assessment results also showed the progress that students made since they all had an opportunity to teach. Each student was very interested in the progress the class made during their individual teaching lesson. This is one example of the student-centered teaching process. What we have learned from this specific exercise is that first, we need to understand the students' learning styles. Secondly, we need to integrate classroom management with our teaching approaches. If more students can be actively involved in the teaching and learning process, we may have less classroom discipline problems. However, classroom management is always a challenge for teachers and we have a lot to learn about it. Our next teacher training program will provide more guidance on classroom management.

\section{Conclusions}

To serve the needs of our diverse student populations and families, we need to train our teachers in the following areas:

To first understand ourselves. From where we come from to what we have been through in our adolescent years-our multicultural development have affected us and influenced our perspective on life. Our personal knowledge and experiences can enhance our own learning experiences and teaching methods in the classroom.

Second, we need to preserve the connections students have with their families and cultural backgrounds. It is not for us to judge our students and their family backgrounds, but to understand and learn to better integrate and accommodate those differences in our classroom instruction. We should realize that diversity is a very rich resource for the class, for our schools and for our society.

Third, we need to learn how to teach for social equality. As teachers, we need to combine the knowledge that students need to learn and the real life experiences they have. All of these social equality concepts can be displayed in your classroom environment setting, in the selection of your text book and teaching materials, and in your daily classroom activities and discussions. We need to work hard to provide all students with successful learning experiences in their lives.

\section{References}

Banks, J. A. (2006). Cultural diversity and education: Foundations, curriculum, and teaching (5th ed.). Boston and New York: Pearson Education.

Biggs, J. B. (1996). Western misperceptions of the Confucian-heritage learning cultures. The Chinese learner: Cultural, psychological and contextual influences. Hong Kong: CERC and ACER. 
Biggs, J. B., Kember, D., \& Leung, Y. P. (2001). The revised two-factor study process questionnaire: R-SPQ-2F. British Journal of Educational Psychology, 71, 133-149.

Causey, V. E., Thomas, C. D., \& Armento, B. J. (2000). Cultural diversity is basically a foreign term to me: The challenges of diversity for preservice teacher education. Teaching and Teacher Education, 16, 33-45.

Easter, L. M., Shultz, E. L., Neyhart, T. K., \& Reck, U. M. (1999). Weighty perceptions: A study of the attitudes and beliefs of preservice teacher education students regarding diversity and urban education. The Urban Review, 31, 205-220.

Gay, G., \& Howard, T. (2000). Multicultural teacher education for the 21st century. The Teacher Educator, 36(1), 1-16.

Genesee, F. (1994). Integrating language and content: Lessons from immersion (Educational practice report 11, National Center for Research on Cultural Diversity and Second Language Learning, Washington, DC: Center for Applied Linguistics).

HE, A. (1999). Socialization through teacher's directives: Cases from Chinese heritage language classrooms in the US. Paper presented at American Association for Applied Linguistics, Stamford.

HE, K. K. (2002). Principles and strategies for reforming teacher education in China. Retrieved from http://www.edu.cn/20010823/207538.shtml

HUANG, W. (2002). Professionalization of teacher education and reform of curriculums. Retrieved from http://www.edu.cn/20010905/3000282.shtml

Irvine, J. J. (2003). Educating teachers for diversity: Seeing with a cultural eye. New York: Teachers College Press.

Johnson, K. E. (1996). The vision versus the reality: The tensions of the TESOL practicum. In D. Freeman \& J. Richards (Eds.), Teacher learning in language teaching (pp. 30-49). New York: Cambridge University Press.

Kember, D., \& Gow, L. (1994). Orientations to teaching and their effect on the quality of student learning. Journal of Higher Education, 65, 58-74.

Kramsch, C. (1994). Context and culture in language teaching. Oxford: Oxford University Press.

Ladson-Billings, G. (2000). Fighting for our lives: Preparing teachers to teach African American students. Journal of Teacher Education, 51(3), 206-214.

Lakoff, G. (1987). Woman, fire and dangerous things: What categories reveal about the mind. Chicago: University of Chicago Press.

Lee, J. F., \& Vanpatten, B. (2003). Making communicative language teaching happen. New York: McGraw Hill.

LIAO, C. (1997). Comparing directives: American English, Mandarin and Taiwanese English. Taipei: Crane Publishing.

LIU, J. (2002). On development of teacher education in the new millennium. Retrieved from http://www.edu.cn/20030519/3085008.shtml

Milner, H. R., \& Smithey, H. (2003). How teacher educators created a course curriculum to challenge and enhance preservice teachers' thinking and experience with diversity. Teaching Education, 14(3), 293-305.

Milner, H. R., Flowers, L. A., Moore, E., Moore, J. L., \& Flowers, T. (2003). Preservice teachers’ awareness of multiculturalism and diversity. The High School Journal, 87(1), 63-70.

Ministry of Education. (1999). Twenty years of education in China under the guidance of Deng Xiaoping’s Theory. Retrieved from http://www.moe.edu.cn/wenxian/cedu20/cedu20s_index.htm

Ministry of Education. (2001). Directive on reforming and developing teacher education in the 10th five-year period. Beijing, China.

Myers, D. (1997). Teaching culture with language: Words of foreign origin and linguistic purism. Journal of the Chinese Language Teachers' Association, 32, 41-55.

Northfield, J., \& Gunstone, R. (Eds.). (1997). Teaching about teaching: Purpose, passion and pedagogy in teacher education (pp. 48-56). London: Falmer Press.

Resnick, L. B. (2006). Foreign language instruction: Implementing the best teaching methods. Research Points, 4(1), 1-4.

Saville-Troike, M. (1996). The ethnography of communication. In S. McKay, N. Hornberger, \& S. L. McKay (Eds.), Sociolinguistics and language teaching (pp. 351-82). Cambridge: Cambridge University Press.

SHI, L. (2002). A review of research on school-based staff development in China. Retrieved from http://www.edu.cn/20030109/3075639_4.shtml

SHI, Q. H. (2002). On reforming curriculum design for teacher education. Retrieved from http://www.edu.cn/20010823/207979.shtml

State Council. (2001). State Council's decision on reforming and developing basic education. Beijing, China.

Velez-Rendon, G. (2002). Second language teacher education: A review of the literature. Foreign Language Annals, 35(4), $457-467$.

Villegas, A. M., \& Lucas, T. (2002). Educating culturally responsive teachers: A coherent approach. Albany, NY: State University of New York Press.

Widdowson, H. G. (1998). Context, community, and authentic language. TESOL Quarterly, 32, 705-716. 


\section{Appendix: Questionnaire in Star Talk 2009 Summer Institute}

\section{Pre-survey: Star Talk 2009 Summer Institute}

1. Do you currently hold a teaching license?

2. Are you currently working on your teaching license requirements?

3. Are you employed as a language teacher?

4. What language(s) do you teach or will you teach?

5 . What is your gender?

6. What do you hope to learn/gain from this Star Talk workshop?

7. Think back to your own language learning experiences. What was the role of the teacher? What expectations did the teachers have for the students?

8. What are some of the differences between language classrooms in the U.S. and language classrooms in your home country?

9. What do you believe (or will be) the biggest challenges for teaching the students in U.S. schools?

10. What concerns do you have regarding your responsibilities as a language teacher in the U.S. schools?

\section{Post-survey: Star Talk 2009 Summer Institute}

1. Do you currently hold a teaching license?

2. Are you currently working on your teaching license requirements?

3. Are you employed as a language teacher?

4. What language(s) do you teach or will you teach?

5. What is your gender?

6. What have you been able to use from information learned in the summer institute?

7. What challenges have you faced in implementing collaborative, learner-centered instruction and/or assessment?

8. Were you able to overcome these challenges, if so how?

9. What are your perceptions now about your role as an Arabic/Chinese teacher? In what ways have your ideas/perceptions changed?

10. What other kinds of professional development do you feel you need to transition to US teaching? 